\title{
MİDYE ÖRNEKLERİNDE VIBRIO PARAHAEMOLYTICUS'A KARŞI KORUK, LIMON VE NAR SUYUNUN ANTİBAKTERIYYEL ETKİSİ
}

\author{
Fatma Öztürk* \\ İzmir Kâtip Çelebi Üniversitesi, Su Ürünleri Fakültesi, İzmir, Türkiye
}

Geliş / Received: 07.02.2020; Kabul / Accepted: 07.05.2020; Online bask1 / Published online: 11.05.2020

Öztürk, F. (2020) Midye örneklerinde Vibrio parahaemolyticus'a karşı koruk, limon ve nar suyunun antibakteriyel etkisi. GIDA (2020) 45(3) 506-516 doi: 10.15237/gida.GD20024

Öztürk, F. (2020). Antibacterial effect of unripe grape lemon and pomegranate juice against Vibrio parabaemolyticus in mussels samples. GID A (2020) 45(3) 506-516 doi: 10.15237/gida.GD20024

\section{ÖZ}

Bu çalıșmada, koruk, limon ve nar suyunun Vibrio parabaemolyticus'a karșı antibakteriyel etkisi araștırlmıștır. Bu amaçla, midye örneklerine yaklaşı $10^{7} \mathrm{KOB} / \mathrm{g} V$. parahaemolyticus inokule edilmiştir. İnokülasyon yapılan midye örnekleri 0, 30, 60 ve $90 \mathrm{dk}$ koruk, limon ve nar suyunda bekletilmiș ve $4{ }^{\circ} \mathrm{C}$ 'da 6 gün boyunca depolanmıștır. Depolama periyodunda, $V$. parahaemolyticus sayısı, $\mathrm{pH}$ ve titre edilebilir asitlik belirlenmiş ve duyusal parametreler açısından değerlendirilmiştir. Araştırma sonucunda, en yüksek antibakteriyel etki koruk suyu uygulanan deneme gruplarında görülmüştür $(P<0.05)$. Denemenin 0 . gününde koruk, limon ve nar suyu uygulanan gruplardaki $V$. parahaemolyticus sayısı, konsantrasyona bağlı olarak sırasıyla 2.22-2.64; 1.58-1.85 ve 1.44-1.71 log KOB/g düzeyinde azalma göstermiştir. Bu azalma eğilimi depolamanın diğer günlerinde de devam etmiştir. Duyusal değerlendirme sonucunda, nar suyunun, midye örneklerinin renk ve görünüşünü olumsuz etkilediği belirlenmiştir $(P<0.05)$. Araştırma sonunda, ev uygulamalarında kullanılan sofra tipi asitleştiricilerin, özellikle koruk suyunun yüksek düzeyde antibakteriyel etkisinin olduğu, su ürünlerinde gıda güvenliğin sağlanması için kullanılabileceği belirlenmiştir.

Anahtar kelimeler: Midye, Vibrio parahaemolyticus, koruk, limon, nar, antibakteriyel etki

\section{ANTIBACTERIAL EFFECT OF UNRIPE GRAPE, LEMON AND POMEGRANATE JUICE AGAINST VIBRIO PARAHAEMOLYTICUS IN MUSSELS SAMPLES}

\begin{abstract}
In this study, antibacterial effect of koruk (unriped grape), lemon and pomegranate juice against Vibrio parabaemolyticus was investigated. For this purpose, approximately $10^{7} \mathrm{CFU} / \mathrm{g} V$. parahaemolyticus were inoculated into mussel samples. Inoculated mussel samples were treated with koruk, lemon and pomegranate juice for $0,30,60$ and 90 minutes and stored at $4{ }^{\circ} \mathrm{C}$ for 6 days. During the storage period, $V$. parabaemolyticus number, $\mathrm{pH}$ and titratable acidity value were determined and evaluated in terms of sensory parameters. As a result of the research, the highest antibacterial effect was detected in the koruk juice groups $(P<0.05)$. On the 0 th day of the experiment, the number of $V$.parabaemolyticus in the groups that were applied koruk, lemon and pomegranate juice were decreased by $2.22-2.64 ; 1.58-1.85$, and $1.44-$ $1.71 \log \mathrm{CFU} / \mathrm{g}$, respectively. This downward trend continued on other storage days. Sensory evaluation revealed that pomegranate juice negatively affected the color and appearance of mussel samples $(P<0.05)$. As a result, it has been determined that acidic acidifiers used in home applications, especially the koruk juice has a high antibacterial effect, and can be used for food safety in seafood.
\end{abstract}

Keywords: Mussel, Vibrio parabaemolyticus, koruk, lemon, pomegranate, antibacterial effect

\footnotetext{
${ }^{*}$ Yazışmalardan sorumlu yazar/ Corresponding author

凶: fatma.ozturk@ikc.edu.tr

留 (+90) $2323293535 / 4215$

且 $(+90) 2323250535$
}

Fatma Öztürk; ORCID no: 0000-0003-4763-3801 


\section{GİRIŞ}

Akdeniz midyesi (Mytilus galloprovincialis) Mytilae ailesine aittir ve Akdeniz ülkelerinde yetiştirilen çok popüler bir yumuşakça türüdür (Bingol vd., 2008). Sucul çevrenin doğal bir parçası olan midyeler, zengin organik madde içeriği ile ekonomik değere sahip olan önemli ve besleyici deniz canlilarından biridir (Kayhan vd., 2016). Kaliteli ve ucuz protein kaynağıdır. Çoklu doymamış yağ asitleri bakımından zengin, düşük yağlı ve düşük kolesterollü bir gidadır (Erkan, 2005). İz elementler (selenyum, kalsiyum, demir, magnezyum ve fosfor), vitaminler (A, B1, B2, B6, B12, C, D ve E) ve glikojen bakımından da çok zengindir (Bingol vd., 2008; Tosun vd., 2018).

Yaşadıkları sucul ortamdaki suyu filtre ederek beslenen midyeler, patojenler de dahil olmak üzere birçok mikroorganizmayı bünyelerinde biriktirmektedir (Tosun vd., 2018). Ayrıca, yüksek glikojen ve serbest aminoasit içeriği, yüksek su aktivitesi $\left(a_{\mathrm{w}}>0.95\right)$ ve nötr $\mathrm{pH}$ (6.7-7.1) değeri, midyeleri mikroorganizmaların gelişebileceği ideal bir substrat yapmaktadır (Bingol vd., 2008; Tosun vd., 2018).

Çiğ veya az pişmiş kabuklu su ürünlerinin tüketiminden kaynaklanan gida kaynaklı enfeksiyonlar yaygin olarak görülmektedir (Kayhan vd., 2016; Tosun vd., 2018). Kabuklu su ürünlerinden izole edilen ve gida enfeksiyonuna neden olan ölümcül insan patojenleri arasinda Vibrio parahaemolyticus, $V$. cholerae ve $V$. vulnificus önde gelmektedir (Camkerten vd., 2017; Nawi vd., 2017). ABD'de, ylllk olarak yaklaşı 35.000 $V$. parahaemolyticus kaynaklı gida enfeksiyonu görülmekte ve bunlarnn çoğu çiğ veya az pişmiş kabuklu su ürünlerinin tüketiminden kaynaklanmaktadır (Newton vd., 2014). Bu ürünlerin tüketimi sonucu oluşan hastalıkların önlenebilmesinde en önemli nokta, tüketim öncesinde ete uygulanacak olan isslemlerle ürünün güvenlik seviyesinin arttırılmasıdır (Ibrahim vd., 2018).

İşlenmiş gidalarda mikrobiyel gelişimi engellemek amaciyla sentetik katk1 maddeleri yaygin olarak kullanilmaktadır. Ancak, bu maddelerin güvenilirlikleri üzerinde oluşan endişelerden dolayı doğal katkı maddelerine olan ilgi artmıstır (Ibrahim vd., 2018). Doğal koruyuculara yönelik artan eğilim, gıdaların kalitesini ve güvenliğini artırmak için sitrik, asetik ve laktik asit gibi zayıf organik asitlerin kullanımını gündeme getirmiştir (Bingol vd., 2011; Abd-El-Malek ve El-khateib, 2018; Ozturk ve Sengun, 2019). Organik asitler ve doğal asidik meyve suları, gidalanın işlenmesi sirasinda bozulmaya neden olan ve patojenik mikroorganizmaların büyümesini ve hayatta kalmasını kontrol etmek için kullanılmaya başlanmıştır (Karabiyikli ve Öncül, 2016). Organik asitlerin patojenik bakteriler üzerindeki etkisi kapsamlı bir şekilde araştırrlsa da, bu asitlerin su ürünlerinde kullanımına yönelik çok az veri bulunmaktadır (Mathur ve Schaffner, 2013).

Meyve ve sebzelerin yapısında malik, sitrik, süksinik ve tartarik asit gibi pek çok organik asit bulunmaktadır. Yapılan çalışmalarda koruk, limon, nar, pırasa, soğan, üzüm gibi çeşitli meyvesebze ve sularını antimikrobiyel etkisinin, çoğunlukla yapılarında bulunan organik asitlerden kaynaklandığı bildirilmiştir (Karapinar ve Sengun, 2007; Saeedi vd., 2017; Ibrahim vd., 2018, Lytou vd., 2018).

Limon suyu; doğal, ucuz ve güvenli olduğu için gerek aroma vermek gerekse antibakteriyel olarak gidalarda yaygin olarak kullanılmaktadır (Abd-ElMalek ve El-khateib, 2018). Limon, antimikrobiyel aktiviteyi arttıran limonoidler, polimetoksi flavonlar, flavon glikozitler dahil bir grup flavonoid içermektedir. Sitrik asit, limon suyunun önemli bir bileşenidir, yaklaşı $0.056 \mathrm{~g} / \mathrm{g}$ oraninda bulunur ve antibakteriyel aktiviteden sorumludur (Mathur ve Schaffner, 2013; Alfonzo vd., 2017; Ibrahim vd., 2018).

Nar (Punica granatum L.) polifenolik bileşikler (gallocatechins, delphinidin, cyanidin ve pelargonidin) bakımından zengin bir meyvedir (Naz vd., 2007; Betanzos-Cabrera vd., 2015). Son yıllarda yapılan çalışmalarda, nar ekstraktlarının antimikrobiyel ve antiviral aktiviteye sahip olduğu ortaya konulmuştur (Naz vd., 2007; Ibrahim vd., 2018; Lytou vd., 2018). Ancak, yüksek antioksidan kapasiteye sahip nar suyunun antimikrobiyel aktivitesi üzerinde çok az sayıda çalısma 
bulunmaktadır (Türkyılmaz vd., 2013; BetanzosCabrera vd., 2015).

Üzüm meyvesinin olgunlaşmamış hali "koruk" (Vitis vinifera L.) olarak bilinmektedir. Koruk suyu, olgunlaşmamış üzümlerin sıkılmasıyla elde edilen bir içecektir (Çevik vd., 2016). Akdeniz ülkelerinde sirke ve limon suyu gibi yemekler, salatalar ve mezeler için asitleştirici ve aroma verici olarak kullanilır (Çevik vd., 2016; Ozturk ve Sengun, 2019, Sengun vd., 2019). Koruk, düşük şeker içeriğine sahip bir meyvedir ve yüksek miktarda tartarik ve malik asit içerir (Ozturk ve Sengun, 2019). Koruk suyunun, kafeik asit, kateşin, epikateşin, gallik asit, kumarik asit, protokatekik asit, quercetin, quercetin glikozit ve tirozol gibi fitokimyasal bileşikler içerdiği bildirilmiştir (Karabiyikli ve Öncül, 2016; Ozturk ve Sengun, 2019; Sengun vd., 2019). Koruk suyunun, asidik özelliği ve yapısında bulunan fenolik bileşenler, antioksidan etkisinin yanı sıra antimikrobiyel aktivite göstermesine de olanak sağlamaktadır. Ancak, koruk suyunun antimikrobiyel etkisi üzerine yürütülen çalışma sayısı birkaç adet ile sınırlıdır (Karapinar ve Sengun, 2007; Karabiyikli ve Öncül, 2016; Ozturk ve Sengün, 2019).

Gıdalara tat vermek için kullanılan asidik sıvılar antimikrobiyel etkilere sahiptir. Limon suyu, su ürünleri etlerin marine edilmesi için en yaygın kullanılan ürünlerden birisidir. Ancak, nar suyu ve koruk suyunun su ürünlerinde kullanımına yönelik yapılmış bir çalışmaya rastlanılmamışır. Bu çalışmada, farklı sürelerde koruk, limon ve nar suyunda bekletilen midye etlerinde $V$. parabaemolyticus'un canlı kalma düzeyinin belirlenmesi amaçlanmıştır. Ayrıca, kullanılan asidik sıvıların midye etlerinin duyusal özellikleri üzerindeki etkisinin belirlenmesi de hedeflenmiştir.

\section{MATERYAL VE METOT}

\section{Materyal}

Ekim 2019'da Bodrum bölgesinden temin edilen midyeler (Mytilus galloprovincialis) buz içeren strafor kutular içerisinde laboratuvara getirilmiş ve materyal olarak kullanılmıştır. Denemelerde kullanilan Vibrio parabaemolyticus ATCC 17802 suşu İzmir Katip Çelebi Üniversitesi kültür koleksiyonundan temin edilmiştir.

\section{Bakteri inokülümünün hazırlanması}

$V$. parahaemolyticus'un sıvı formdaki stok kültürleri, gliserol içeren (\%20; v/v) TSB besiyerinde $-20 \pm 2$ ${ }^{\circ} \mathrm{C}$ 'da muhafaza edilmiştir. Denemeler için $15 \mathrm{~mL}$ TSB besiyerine stok kültürlerden $150 \mu \mathrm{L}$ aktarilıp, $37{ }^{\circ} C^{\prime}$ da 24 saat inkübe edilerek aktifleştirilmiştir. Aktif bakteri kültürleri santrifüj tüplerine aktarılmış ve $15 \mathrm{dk}$ boyunca $6000 \mathrm{rpm}$ hizda (Hermle Z206A) santrifüjlenmiştir. Fizyolojik tuzlu su (FTS) kullanılarak süspanse edilen hücre peletleri iki kez daha santrifüjleme işlemiyle yıkanmıştır. Santrifüj sonrasında elde edilen pelet kısmı üzerine FTS eklenerek denemelerde kullanılacak bakteri inokülümleri hazırlanmıştır.

\section{Uygulama solüsyonlarının hazırlanması Koruk suyu üretimi}

Koruk suyu üretimi için Manisa'da yetiştirilen Yediveren cinsi olgunlaşmamış üzümler (Vitis vinifera L.) kullanılmıştır. Demetlerinden ayrılan koruk meyveleri musluk suyuyla yıkandıktan sonra sirkeli suda $(\% 5 \mathrm{v} / \mathrm{v}) \quad 15 \mathrm{dk}$ bekletilip durulanmıştır. Plastik bir küvet içinde ezildikten sonra elle sıkılmıştr. Elde edilen karışım tülbentten süzülerek pet şişelere aktarılmış ve analize kadar $-18{ }^{\circ} \mathrm{C}$ da depolanmıştır. Hazırlanan koruk suyunun $\mathrm{pH}$ ve titre edilebilir asit değeri (TA) 2.69 ve \% 4.5 (tartarik asit) olarak belirlenmiştir.

\section{Limon ve nar suyunun hazırlanmas1}

Limon ve nar meyvesi Izmir'deki yerel bir marketten temin edilmiştir. Meyveler musluk suyuyla yıkanmış ve steril bir bıçakla kesilmiştir. Taze meyve sularını hazırlamak için ev tipi bir meyve sıkacağı kullanılmışır. Elde edilen limon suyunun $\mathrm{pH}$ ve TA değeri 2.52 ve $\% 8.32$ (sitrik asit), nar suyunun $\mathrm{pH}$ 's1 3.33 ve TA değeri $\% 1.92$ (susuz sitrik asit) olarak belirlenmiştir.

Midye örneklerinin $V$. parahaemolyticus ile inokule edilmesi ve meyve sulariyla muamelesi

Midye örnekleri musluk suyuyla y1kandıtan sonra, kabukları \%76'llk alkolle silinmiştir. Steril bıçak kullanılarak eti çıkartılmıstır. Midye 
etlerinde $V$. parahaemolyticus analizi yapilarak, bu patojen bakımında negatif olduğu belirlenmiştir. Midye örneklerinden 100'er g alınarak steril Petri kutularına aktarılmıştır. Bu örnekler üzerine, $V$. parahaemolyticus inokülümlerinden $1 \mathrm{~mL}\left(10^{9}\right.$ $\mathrm{KOB} / \mathrm{mL}$ ) pipetlenmiş ve steril Drigalski spatülü ile bakterinin homojen olarak dağılması sağlanmıştr. Bakteri hücrelerinin ete iyi nüfuz etmesi için $20{ }^{\circ} \mathrm{C}^{\prime} \mathrm{da} 30 \mathrm{dk}$ bekletilmiştir. Bu şekilde hazırlanan ve yalnızca bakteri içeren grup kontrol grubu olarak değerlendirilmiştir. Diğer deneme gruplarının hazırlanması için, bakteri inoküle edilen midyeler 30, 60 ve $90 \mathrm{dk}$ koruk, limon ve nar suyuna [midye eti/meyve suyu, $1 / 2$ $(\mathrm{w} / \mathrm{v})$ ] daldırllmış ve süre sonunda solüsyonlar süzgeç kullanılarak süzülmüştür. Daha sonra, cam kavanozlara yerleştirilip sıkıca kapatılmış ve 4 -C'da 6 gün boyunca depolanmıştır. Depolamanın $0,1,3$ ve 6 . günlerinde $V$. parabaemolyticus say1s1, $\mathrm{pH}$ ve toplam asitlik değeri tespit edilmiştir.

\section{V. parahaemolyticus sayısının tespiti}

Depolamanın $0,1,3$ ve 6 . günlerinde her bir deneme grubundan 1 kavanoz (100 g) midye örneği alınıp homojen hale getirilmiştir. Bu şekilde hazırlanan örneklerden, rastgele $10 \mathrm{~g}$ alını, 90 mL'lik FTS içerisine ilave edilerek homojenize edilmiştir. Homojenize edilen örneklerden seri dilüsyonlar hazırlanmıştır. Hazırlanan dilüsyonlardan, TCBS (Thiosulfate Citrate Bile Sucrose) Agar (Merck) besiyerine ekim yapilmıştır. $37^{\circ} \mathrm{C}$ 'da 18-24 saat süren inkübasyon sonucunda, küçük mavi-yeşil merkezli kolonilerin sayımlanı gerçekleştirilmiştir (Guin vd., 2019).

\section{pH ve toplam titrasyon asitliği (TA)}

Depolamanın $0,1,3$ ve 6 . günlerinde midye örneklerinin $\mathrm{pH}$ değerleri AOAC (2000)'e göre ölçülmüştür. Toplam asitlik tayini Varlık vd., (2007)'ye göre yapılmıştur.

\section{Duyusal analiz}

Duyusal analizler, bakteri inoküle edilmeyen örneklerde, depolama periyodunun başlangıcında yapılmıştr. Deneme gruplarındaki midye örnekleri vakumla paketlenmiş ve Sous-vide cihazı kullanılarak (75 $\left.{ }^{\circ} C^{\prime} \mathrm{da} \quad 10 \mathrm{dk}\right)$ pişirilmiştir. Pişirilmiş numuneler, 10 panelist tarafindan renk, doku, görünüş, çiğneme özelliği, lezzet ve genel kabul edilebilirlik açısından değerlendirilmiştir. Değerlendirmede, 10 puanlı (9-10: çok iyi; 7-8: iyi; 5-6: orta 3-4: kötü; 1-2: çok kötü) hedonik skala kullanılmıştır (Kılınç ve Yavuz, 2011).

\section{İstatistik analiz}

Deneyler iki tekerrür halinde gerçekleştirilmiştir. Analiz sonuçları ortalama \pm standart hata olarak ifade edilmiştir. Deneysel veriler, SPSS 22 Paket Programı kullanilarak $P \leq 0.05$ anlamlilik düzeyinde tek yönlü ANOVA (varyans analizi) ve Duncan çoklu karşılaştırma yöntemleri ile değerlendirilmiştir.

\section{SONUÇ VE TARTIŞMA Vibrio parahaemolyticus sayıs}

$4{ }^{\circ} \mathrm{C}$ 'da 6 gün boyunca depolanan midye örneklerinde tespit edilen $V$.parahaemolyticus sayıs1 Şekil 1'de verilmiştir. Koruk suyunda 30, 60 ve 90 $\mathrm{dk}$ bekletilen deneme gruplarında 0 . günde tespit edilen $V$. parabaemolyticus sayısı sirasiyla 4.62; 4.55 ve $4.20 \log \mathrm{KOB} / \mathrm{g}$ olarak saptanmıştır. En yüksek antibakteriyel etki koruk suyu uygulanan deneme gruplannda görülmüsstür $(P<0.05)$. 30, 60 ve $90 \mathrm{dk}$ limon suyunda bekletilen gruplarda ise $V$. parahaemolyticus sayisinin 5.26; 4.99 ve $5.06 \mathrm{log}$ $\mathrm{KOB} / \mathrm{g}$ düzeyinde olduğu belirlenmiştir. Limon suyu ve nar suyunun antibakteriyel etkisi arasinda önemli bir fark görülmemiştir $(P>0.05)$. Nar suyuna maruz birakilan deneme gruplarnndaki $V$. parabaemolyticus sayıs $5.13-5.40 \quad \log \mathrm{KOB} / \mathrm{g}$ arasında değişim göstermiş̧ir. Depolamanın 0 . gününde kontrol grubunda tespit edilen $V$. parabaemolyticus say1s1 $6.84 \log \mathrm{KOB} / \mathrm{g}$ olarak belirlenirken, en düşük bakteri sayısı (4.20 log $\mathrm{KOB} / \mathrm{g}$ ) $90 \mathrm{dk}$ koruk suyunda bekletilen deneme grubunda tespit edilmiştir. Koruk, limon ve nar suyunda 30, 60 ve $90 \mathrm{dk}$ bekletilen deneme gruplarındaki $V$. parabaemolyticus sayıs kontrol grubuna kıyasla önemli düzeyde düşük bulunmuştur $(P<0.05)$.

Asetik, sitrik ve laktik asit gibi organik asitler patojen mikroorganizmaların gelişimini kontrol etmek için yaygın olarak kullanılmaktadır (Bingol vd., 2011; Mathur ve Schaffner, 2013; Abd-ElMalek ve El-khateib, 2018). Bunun yanı sıra, farkl1 bitki ekstraktlarının gida sistemlerinde antibakteriyel aktivitesini araştıran birçok çalışma 
vardır (Baydar vd., 2004; Karapinar ve Sengun, 2007). Öte yandan, limon, nar ve koruk suyu gibi ev uygulamalarnnda kullanilan sofra tipi asitleştiricilerin antibakteriyel etkileri hakkında sınırlı sayıda araştırma bulunmaktadır.

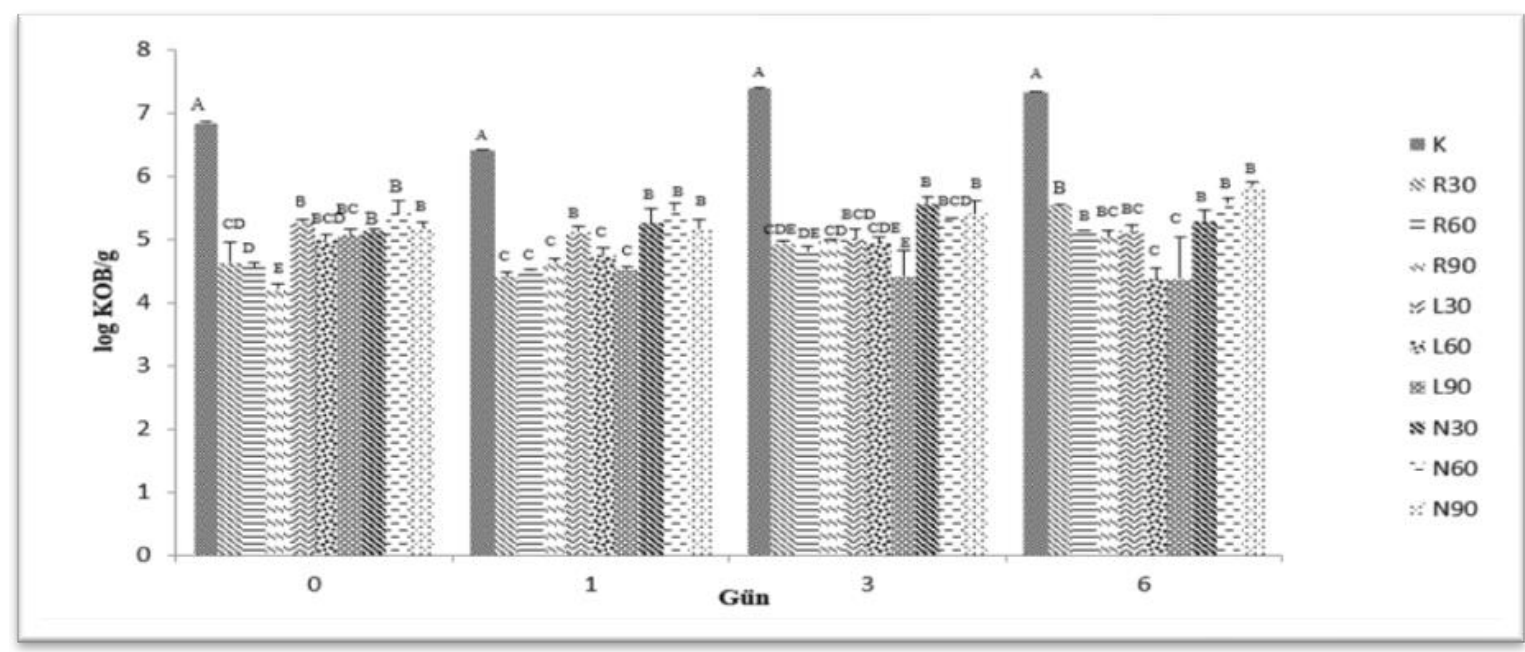

Şekil 1. Midye örneklerinde $V$. parahaemolyticus sayısındaki değişim (K: kontrol; R: koruk suyu; L: limon suyu; N:nar suyu)

Figure 1. Change in the number of $V$. parahaemolyticus in mussel samples (K: control; R: koruk juice; L: lemon juice; N: pomegranate juice)

Üzüm çekirdeği ekstrakt1, sirke ve şarap gibi üzüm ürünlerinin antibakteriyel aktivitesi birçok çalışmada tespit edilmiştir (Xu vd., 2017; Andrade vd., 2019; Fiallos vd., 2019; Kumar vd., 2019; Memar vd., 2019). Ancak, koruk suyunun antibakteriyel etkisinin araştırıldığı yalnızca birkaç adet çalışma bulunmaktadır. Farklı meyve sularının antibakteriyel etkisinin araştırıldığı bu çalışmada, koruk suyu kullanılan deneme gruplarındaki $V$. parahaemolyticus sayıs 2.22-2.64 $\log \mathrm{KOB} / \mathrm{g}$ düzeyinde azalma göstermiştir. Koruk suyunun antibakteriyel etkisi, farklı gida patojenleri üzerinde yürütülen çalışmalarda da ortaya konulmuştur. $\mathrm{Bu}$ çalışmalardan birisi Karapinar ve Sengun (2007) tarafindan yürütülmüş, maydanoz ve salatalık örnekleri $10^{6}$ $\mathrm{KOB} / \mathrm{mL}$ düzeyinde Salmonella Typhimurium ile inoküle edilerek, 0, 15, 30, $60 \mathrm{dk}$ boyunca koruk suyu ile muamele edilmiştir. Başlangıçta $S$. Typhimurium sayıs1 1-1.5 log $\mathrm{KOB} / \mathrm{g}$ azalırken, 15,30 ve $60 \mathrm{dk}$ boyunca koruk suyuna maruz bırakılan örneklerde 2-3.5 log KOB/g düzeyinde azalma tespit edilmiştir. Başka bir çalışmada, koruk suyu ve koruk ekşisinin farklı gida patojenleri üzerine minimum inhibisyon konsantrasyonu belirlenmiştir. En dirençli mikroorganizma $S$. Typhimurium, en hassas mikroorganizma ise Bacillus cereus olarak belirlenmiştir (Karabıyıklı ve Öncül, 2016). Ozturk ve Sengun (2019) tarafindan, koruk suyu ve kurutulmuş koruk posası içeren karışımlar dana etinde marinasyon sıvısı olarak kullanılmıs ve ürün güvenliği üzerindeki etkisi araşturılmıştır. Çalışmada, gıda patojenleri (S. Typhimurium, Escherichia coli O157: $\mathrm{H} 7$ ve Listeria monocytogenes) iki farklı dozda ete inoküle edilerek, $4{ }^{\circ} \mathrm{C}$ 'da 2,24 ve 48 saat marine edilmiştir. $S$. Typhimurium ve E. coli O157:H7 karş1 en etkili solüsyonun MS1 $(\% 50$ koruk suyu $\% 50$ su) ile 48 saatlik marinasyon olduğu, L. monocytogenes için MS2 ( $\% 50$ koruk suyu $+\% 50$ su $+\% 1$ tuz $+\% 0.1$ kekik) ile 24 saatlik marinasyonun etkili olduğu belirlenmiştir. Bir başka çalışmada, koruk suyu ile hazırlanan marine sıvilanının kümes hayvanı etlerinin güvenliği ve kalitesi üzerine etkileri araştırılmıştır. S. Typhimurium ile aşılanan et örnekleri, 1,2 ve 18 saat boyunca $4{ }^{\circ} \mathrm{C}^{\prime} \mathrm{da}$ farkl1 konsantrasyonlardaki koruk suyu ile marine edilmiştir. İşlem sonucunda et örnekleri üzerindeki $S$. Typhimurium sayıları 0.113-3.476 
$\log \mathrm{KOB} / \mathrm{g}$ aralı̆̆ında azalmıştır. S. Typhimurium sayısını azaltmada en etkili sonuç, 18 saat boyunca $\% 100$ koruk suyu ile marine edilerek elde edilmiştir. Araştırma sonuçları, koruk suyunun gıdaların güvenliğini ve kalitesini arttırmak için alternatif marinasyon sivis1 olarak kullanılabileceğini göstermiştir. Olgunlaşmamış üzüm ürünlerinin, yiyecek ve içeceklerde yalnızca asitleştirici ve lezzet verici maddeler olarak değil, aynı zamanda gıda kaynaklı patojenlere karşı antibakteriyel olarak önemli bir potansiyele sahip oldukları görülmektedir.

Limon suyu ve limon meyvesi, çeşitli gıdalarda aroma bileşeni olarak yaygın bir kullanıma sahiptir. Özellikle, Akdeniz havzasında, çiğ veya pişirilerek tüketilen su ürünlerine ilave edilen temel bileşenlerdendir (Alfonzo vd., 2017). Limon suyu, ilave edildiği ürünlerin karakteristik tazeliğini olumsuz etkilemeden, patojenik bakterileri etkisiz hale getiren bir bileşen olarak dikkati çekmektedir (Nawi vd., 2017; Ibrahim vd., 2018). Bu çalışmada, 30, 60 ve $90 \mathrm{dk}$ limon suyunda bekletilen gruplardaki $V$. parahaemolyticus say1s1 sirasiyla $1.58 ; 1.85$ ve $1.78 \log \mathrm{KOB} / \mathrm{g}$ azalmıştır. Çalışmamızda olduğu gibi diğer araşturmacilar tarafindan da, limon suyunun $V$. parabaemolyticus'a karşı antibakteriyel etki gösterdiği belirlenmiştir. Tilapya fileto parçaları $V$. parahaemolyticus ile inoküle edilmiş, $25^{\circ} \mathrm{C}$ ve 4 -C'da 30 ve $120 \mathrm{dk}$ süreyle limon suyuna maruz bırakılmıştır. İncelenen tüm koşullar altında $V$. parahaemolyticus sayısının $5 \log \mathrm{KOB} / \mathrm{g}$ düzeyinde azaldığı bildirilmiştir (Mathur ve Schaffner, 2013). Başka bir çalışmada, çiğ istiridyeye inoküle edilen $V$. parahaemolyticus'un limon suyu ile 30 saniyelik muameleden sonra $4 \quad \log \mathrm{KOB} / \mathrm{g}$ azaldığ1 gözlenmiştir. 60 saniye muamele sonrasında ise $V$. parabaemolyticus tespit edilemediği rapor edilmiştir. Limon suyuyla muamele edilmeyen kontrol grubunda ise $V$. parahaemolyticus sayisinin $3 \log$ $\mathrm{KOB} / \mathrm{g}$ azaldığı bildirilmiştir. $\mathrm{Bu}$ araştırıcılar tarafindan, yalnızca limon suyunun değil, istiridyelerin yapisinda bulunan ve antimikrobiyel özellik taşıyan yapıların, Gram negatif bakterilere karşı savunmada rol alan histon $\mathrm{H} 2 \mathrm{~B}$ proteininin ve baz1 savunma hücrelerinin $V$. parabaemolyticus'un inhibisyonun da etkili olduğu bildirilmiştir (Nawi vd., 2017). Ibrahim vd., (2018) tarafindan, limon suyu (\%50), kekik tozu (4 g/ kg) ve nar kabuğu ekstraktı $(\% 1 \mathrm{v} / \mathrm{w})$ ile marine edilen balık filetolarındaki $V$. parahaemolyticus'un canlı kalma düzeyi araştırlmıştır. Araştırma sonunda, $4{ }^{\circ} \mathrm{C}$ 'da depolama aşamasinda, limon suyu kullanilan grupta 4 . günde $V$. parahaemolyticus sayısının \%100 azaldığı bildirilmiştir. Limon suyunun $V$. parahaemolyticus'a karşı en etkili ajan olduğu görülmüştür. Tomotake vd., (2006) tarafından, Vibrio suşlarının, özellikle $V$. parahemolyticus'un asidik koşullara çok hassas olduğu ve 4.5 'den düşük $\mathrm{pH}$ seviyelerinde kolayca inhibe olduğu bildirilmiştir. Bu bulgu, limon suyunun $V$. parabamolyticus üzerindeki önleyici etkisini açıklamaktadır. Farklı su ürünleri üzerinde yürütülen çalışmalarda $V$. parabaemolyticus sayısındaki azalma birbirinden farklilik göstermektedir, bu farklılığın deneme koşulları ve kullanılan bakteri suşlarından kaynaklandığ1 düşünülmektedir. Ayrıca, Nawi vd. (2017) tarafından da belirtildiği gibi denemelerde kullanılan gıda matrisinin de önemli olduğu kanısına varılmıştır.

Nar ekstraktları ve konsantrelerinin antibakteriyel aktivitesiyle ilgili çok sayıda çalışma bulunmaktadır (Naz vd., 2007; Hayrapetyan vd., 2012; Wu vd., 2016; Ibrahim vd., 2018). Ancak, nar suyunun kullanıldığı çalışma sayısı sınırlı düzeydedir. Nar suyunun antibakteriyel etkisinin araştırildığ bu çalışmada, nar suyunda 30,60 ve $90 \mathrm{dk}$ bekletilen gruplardaki $V$. parahaemolyticus sayısı kontrol grubuna kiyasla $1.71,1.44$ ve 1.65 $\log \mathrm{KOB} / \mathrm{g}$ düzeyinde azalmıştır. BetanzosCabrera vd., (2015) tarafindan yürütülen çalışmada, nar suyunun, Staphylococcus epidermidis'in klinik suşlar1 üzerinde antibakteriyel etki gösterdiği, \%20’lik nar suyunun test edilen 60 suşun tamamını inhibe ettiği belirtilmiştir. Başka bir çalışmada, nar suyu ile marine edilen tavuk göğsü filetoları mikrobiyolojik ve duyusal olarak değerlendirildiğinde, raf ömrünün arttı̆̆1 bildirilmiştir (Lytou vd., 2018), Araşturmacılar tarafindan, antibakteriyel etkinin nar suyunun yapisinda bulunan organik asit ve polifenol bileşiklerinden kaynaklandığ ifade edilmiştir. Organik asitlerin neden olduğu $\mathrm{pH}$ düşüşü, mikroorganizmanın hayatta kalmasını ve çoğalmasını etkileyen birincil faktör olarak gösterilmiştir. 
$\mathrm{pH}$ ve titre edilebilir asitlik (TA) değeri

$4{ }^{\circ} \mathrm{C}$ 'da depolanan midye örneklerinin $\mathrm{pH}$ değerinde meydana gelen değişim Şekil 2'de verilmiştir. Depolamanın 0. gününde koruk, limon ve nar suyunda bekletilen deneme gruplarında $\mathrm{pH}$ değeri sirasiyla 4.53-5.09, 3.994.19 ve 5.10-5.76 arasında değişim göstermiştir. En düşük $\mathrm{pH}$ değerleri limon suyuna maruz bırakilan gruplarda tespit edilmiştir. Farklı uygulamalara maruz birakilan deneme gruplarının hepsinin $\mathrm{pH}$ değerleri kontrol grubuna kiyasla önemli düzeyde düşük bulunmuştur $(P<0.05)$. Depolama süresine bağlı olarak deneme gruplarının $\mathrm{pH}$ değerleri arasında önemli bir değişim olmadığı belirlenmiştir $(P>0.05)$.

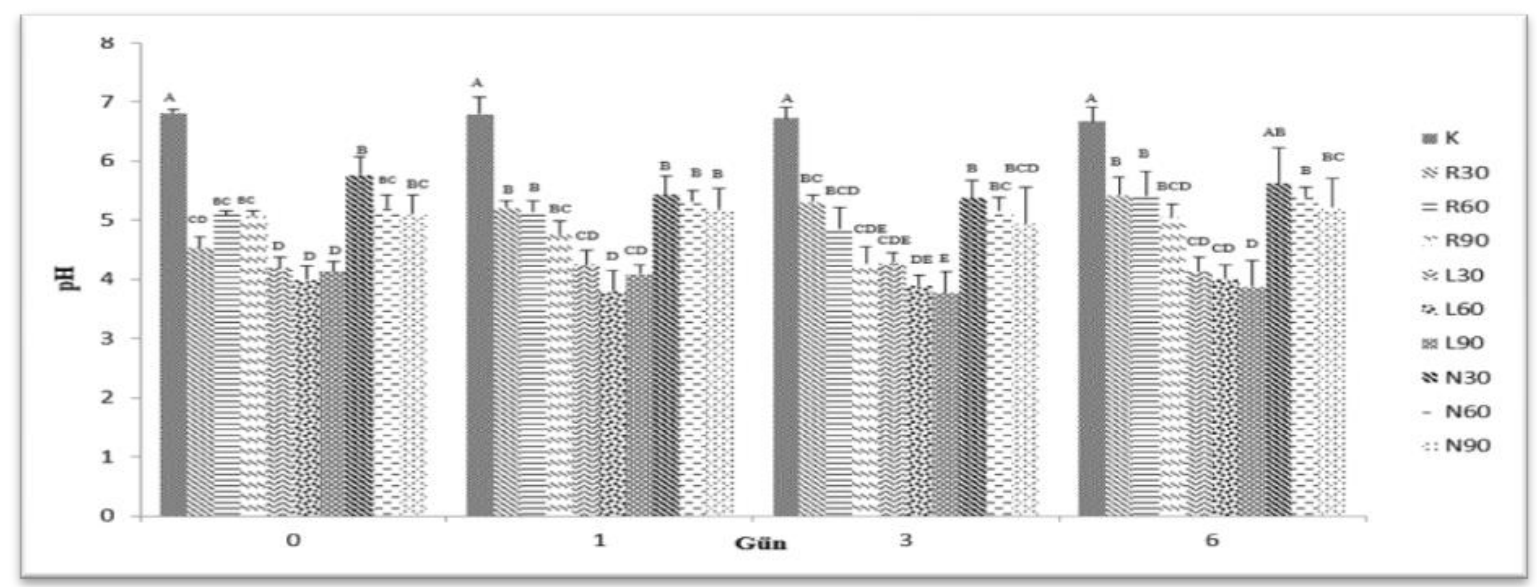

Şekil 2. Midye örneklerinin $\mathrm{pH}$ değerindeki değişim

(K: kontrol; R: koruk suyu; L: limon suyu; N:nar suyu)

Figure 2. Change in $p H$ of mussel samples

(K: control; R: koruk, juice; L: lemon juice; $N$ : pomegranate juice)

$\mathrm{Bu}$ çalışmada, 0 . günde midye etinin $\mathrm{pH}$ değeri 6.81 olarak belirlenmiş, limon suyunda bekletilen gruplarda pH'nın 3.99-4.19 düzeyine düştüğü saptanmıştır. Kışla (2007) tarafindan yürütülen çalışmada da benzer sonuçlara ulaşılmışır. Araştırmacı tarafindan midye dolmanın $\mathrm{pH}$ değeri 6.57 olarak belirlenirken, limon suyu ve limon sosu ile muamele edilen numunelerde $\mathrm{pH}$ 'nın 3.63 ve 3.78'e düzeyine düştüğü bildirilmiştir.

$4{ }^{\circ} \mathrm{C}$ 'da depolanan midyenin TA değerinde meydana gelen değişim Şekil 3'te verilmiştir. Koruk, limon ve nar suyunda bekletilen midye etlerinin asitlik düzeyinin \%0.90-1.35, 4.20-6.00 ve 0.90-1.28 arasında değişim gösterdiği belirlenmiștir. Limon suyuna maruz birakılan örneklerin en yüksek asitlik değerine sahip olduğu tespit edilmiştir $(P<0.05)$.

\section{Duyusal değerlendirme}

Farklı sürelerde koruk, limon ve nar suyunda bekletilen midye örneklerinde duyusal değerlendirme yapılmış, elde edilen sonuçlar renk, doku, görünüş, çiğneme özelliği, lezzet ve genel kabul edilebilirlik açısından Çizelge 1'de ifade edilmiştir. Limon ve koruk suyunda bekletilen deneme grupları ile kontrol grubunun renk ve görünüş puanları arasında önemli bir fark tespit edilmemiştir $(P>0.05)$. Nar suyunda bekletme işlemi midye etinin renk ve görünüşünü olumsuz etkilemiştir $(P<0.05)$. Nar suyundan kaynaklanan renklenmenin panelistler tarafindan beğenilmediği saptanmıştır. Kontrol grubu ve diğer deneme gruplarının koku ve çiğneme özellikleri arasında anlamlı bir fark görülmemiştir $(P>0.05)$. Lezzet bakımından en düşük puanı, nar suyuyla muamele edilen deneme grupları almıştır $(P<0.05)$. Genel kabul edilebilirlik açısından değerlendirildiğinde en yüksek puan, $30 \mathrm{dk}$ limon suyunda bekletilen deneme grubunda saptanmıştur $(P<0.05)$.

Kabuklu su ürünlerinden olan midye, farkl1 şekillerde işlenerek değerlendirilmektedir (Ayvaz, 
2018). Ülkemizde daha çok midye tava ve midye dolma şeklinde tüketime sunulmaktadır (Güngörür ve Mol, 2019). Limon suyu, midye etine lezzet katmak amaciyla yaygin olarak kullanılmaktadır. Bu çalışmada, $30 \mathrm{dk}$ süreyle limon suyuna maruz birakilan midyelerin, alışılagelmiş bir lezzete sahip olmasından dolayı daha çok beğenildiği düşünülmüştür.

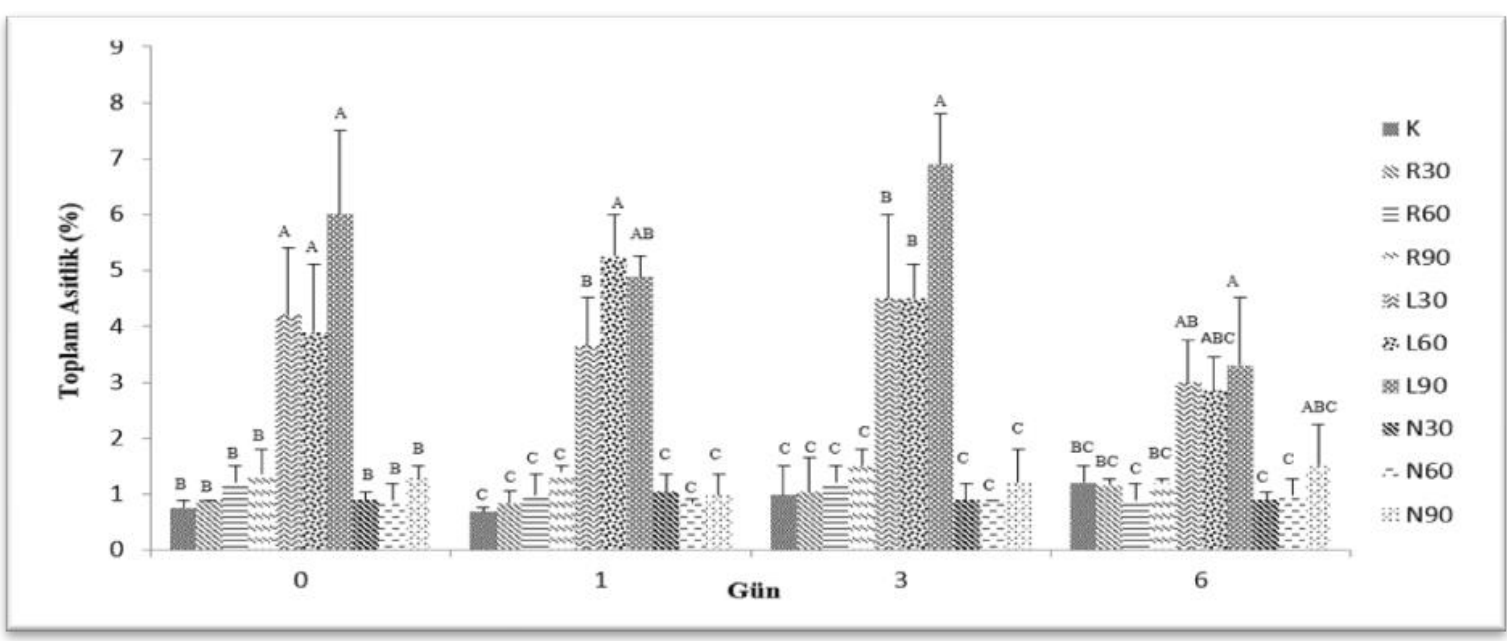

Şekil 3. Midye örneklerinin titre edilebilir asitlik değerindeki değissim (K: kontrol; R: koruk suyu; L: limon suyu; N:nar suyu)

Figure 3. Change in titratable acidity value of mussel samples (K: control; R: koruk juice; L: lemon juice; N: pomegranate juice)

Çizelge 1. Midye örneklerinin duyusal değerlendirme sonuçları Table 1. Sensory evaluation results of mussel samples

\begin{tabular}{|c|c|c|c|c|c|c|}
\hline & $\begin{array}{l}\text { Renk } \\
\text { Color }\end{array}$ & $\begin{array}{c}\text { Koku } \\
\text { Odor }\end{array}$ & $\begin{array}{l}\text { Görünüş } \\
\text { Appearance }\end{array}$ & $\begin{array}{l}\text { Çiğgneme } \\
\text { Özelliği } \\
\text { Chewiness }\end{array}$ & $\begin{array}{c}\text { Lezzet } \\
\text { Flavor }\end{array}$ & $\begin{array}{c}\text { Genel Kabul } \\
\text { Edilebilirlik } \\
\text { Overall } \\
\text { Acceptability }\end{array}$ \\
\hline L30 & $8.33 \pm 1.49^{\mathrm{A}}$ & $8.22 \pm 1.23^{\mathrm{A}}$ & $8.56 \pm 1.17 \mathrm{~A}$ & $7.56 \pm 1.71 \mathrm{~A}$ & $8.22 \pm 1.81^{\mathrm{A}}$ & $8.11 \pm 1.52^{\mathrm{A}}$ \\
\hline L60 & $8.56 \pm 1.17 \mathrm{~A}$ & $7.89 \pm 1.45^{\mathrm{A}}$ & $8.44 \pm 1.71^{\mathrm{A}}$ & $7.67 \pm 1.56^{\mathrm{A}}$ & $7.33 \pm 1.70^{\mathrm{AB}}$ & $7.22 \pm 1.55^{\mathrm{ABC}}$ \\
\hline L90 & $8.67 \pm 1.05^{\mathrm{A}}$ & $8.11 \pm 1.45^{\mathrm{A}}$ & $8.44 \pm 1.07 \mathrm{~A}$ & $7.00 \pm 2.26^{\mathrm{A}}$ & $7.0 \pm 2.05^{\mathrm{AB}}$ & $7.67 \pm 1.63 \mathrm{ABC}$ \\
\hline N30 & $5.22 \pm 2.94^{\mathrm{B}}$ & $7.11 \pm 2.42^{\mathrm{A}}$ & $5.56 \pm 2.67^{\mathrm{B}}$ & $6.33 \pm 2.36^{\mathrm{A}}$ & $6.00 \pm 2.05^{\mathrm{B}}$ & $6.22 \pm 2.15^{\mathrm{ABC}}$ \\
\hline N60 & $5.11 \pm 2.92^{\mathrm{B}}$ & $6.67 \pm 2.45^{\mathrm{A}}$ & $5.11 \pm 2.02^{\mathrm{B}}$ & $6.11 \pm 2.18^{\mathrm{A}}$ & $6.11 \pm 2.38^{\mathrm{B}}$ & $4.89 \pm 2.06^{\mathrm{C}}$ \\
\hline N90 & $5.22 \pm 2.82^{\mathrm{B}}$ & $7.00 \pm 2.21^{\mathrm{A}}$ & $4.89 \pm 2.47^{\mathrm{B}}$ & $6.11 \pm 1.85^{\mathrm{A}}$ & $5.78 \pm 2.15^{\mathrm{B}}$ & $5.67 \pm 2.00^{\mathrm{BC}}$ \\
\hline R30 & $8.00 \pm 1.25^{\mathrm{A}}$ & $8.22 \pm 1.23^{\mathrm{A}}$ & $8.00 \pm 1.56^{\mathrm{A}}$ & $7.89 \pm 1.52^{\mathrm{A}}$ & $7.56 \pm 1.71^{\mathrm{AB}}$ & $7.56 \pm 1.57^{\mathrm{AB}}$ \\
\hline R60 & $8.33 \pm 1.15^{\mathrm{A}}$ & $8.22 \pm 1.23^{\mathrm{A}}$ & $8.56 \pm 1.07 \mathrm{~A}$ & $7.44 \pm 1.26^{\mathrm{A}}$ & $7.56 \pm 1.42^{\mathrm{AB}}$ & $7.33 \pm 1.41 \mathrm{ABC}$ \\
\hline R90 & $6.89 \pm 1.10^{\mathrm{AB}}$ & $7.11 \pm 1.59^{\mathrm{A}}$ & $7.44 \pm 1.07 \mathrm{~A}$ & $6.89 \pm 0.74 \mathrm{~A}$ & $6.56 \pm 1.57 \mathrm{AB}$ & $6.56 \pm 1.17 \mathrm{ABC}$ \\
\hline $\mathrm{K}$ & $7.56 \pm 1.34^{\mathrm{A}}$ & $7.78 \pm 1.23^{\mathrm{A}}$ & $7.44 \pm 1.50^{\mathrm{A}}$ & $6.56 \pm 0.83^{\mathrm{A}}$ & $6.33 \pm 1.05^{\mathrm{AB}}$ & $6.67 \pm 0.82^{\mathrm{ABC}}$ \\
\hline
\end{tabular}

K: kontrol; L: limon suyu; N: nar suyu; R: koruk suyu

K: control; L: lemon juice; N: pomegranate juice; R: koruk. juice

A, B, C $(\downarrow)$ : Aynı harfleri taşıyan ortalamalar arasındaki fark istatistik olarak önemli değildir $(P>0.05)$

A, B, C $(\downarrow)$ : The difference between averages having the same letters is not statistically significant $(P>0.05)$ 
Koruk suyunun, midye etlerinin duyusal parametreleri üzerinde önemli bir değişime neden olmadığ1 belirlenmiştir. Benzer bir çalışmada, koruk suyu ve kurutulmuş koruk posasıyla hazırlanan marinasyon sıvısının sığır etinin renk ve doku parametreleri üzerinde anlamlı bir fark oluşturmadığı belirtilmiştir. Ayrıca, lezzet ve genel kabul edilebilirlik açısından, koruk suyunun etin duyusal kalite özelliklerine katkıda bulunduğu rapor edilmiştir (Ozturk ve Sengun, 2019).

Araştırma sonucunda, ev tipi asitleştiricilerin, özellikle koruk suyunun yüksek düzeyde antibakteriyel etkisinin olduğu, su ürünlerinde gıda güvenliğin sağlanması için kullanılabileceği belirlenmiştir.

\section{KAYNAKLAR}

Abd-El-Malek, A., El-khateib, T. (2018). Prevalence of Listeria monocytogenes in ready-to-eat fish and its control by fresh lemon juice. Prevalence, 3(2): 49-57.

Alfonzo, A., Martorana, A., Guarrasi, V., Barbera, M., Gaglio, R., Santulli, A., Francesca, N. (2017). Effect of the lemon essential oils on the safety and sensory quality of salted sardines (Sardina pilchardus Walbaum 1792). Food Control, 73: 12651274, doi: 10.1016/j.foodcont.2016.10.046.

Andrade, M. A., Lima, V., Sanches Silva, A., Vilarinho, F., Castilho, M.C., Khwaldia, K., Ramos, F. (2019). Pomegranate and grape byproducts and their active compounds: are they a valuable source for food applications?. Trends in Food Sci Technol, 86: 68-84, doi: 10.1016/j.tifs.2019.02.010.

AOAC. (2000). Official methods of analysis. Association of official analytical chemist (17th ed). Arlington, Washington DC.

Ayvaz, Z. (2018). Geleneksel bir ürün olarak "Midye Dolma" ve gelecek önerileri. Ziraat Mühendisligi, 366: 21-27.

Baydar, N.G., Özkan, G., Sağdiç, O. (2004). Total phenolic contents and antibacterial activities of grape (Vitis vinifera L.) extracts. Food Control, 15(5): 335-339. doi:10.1016/S0956-7135(03)00083-5.
Betanzos-Cabrera, G., Montes-Rubio, P.Y., Fabela-Illescas, H.E., Belefant-Miller, H., Cancino-Diaz, J. C. (2015). Antibacterial activity of fresh pomegranate juice against clinical strains of Staphylococcus epidermidis. Food Nutr Res, 59(1): 27620, doi: 10.3402/fnr.v59.27620.

Bingol, E.B., Cetin, O., Muratoglu, K. (2011). Effect of lemon juice on the survival of Salmonella Enteritidis and Escherichia coli in cig kofte (raw meatball). Br Food J, 111(9): 1183-1194, doi: 10.1108/00070701111174604.

Bingol, E.B., Colak, H., Hampikyan, H., Muratoglu, K. (2008). The microbiological quality of stuffed mussels (Midye Dolma) sold in Istanbul. B Food J, 110(11): 1079-1087, doi: 10.1108/00070700810917992.

Camkerten, I., Avsever, M.L., Aksoy, A. (2017). First isolation of Vibrio furnissii (emerging Vibrio) from mussels (Mediterranean mussel and bearded mussel) in Turkey. Ankara Üniv Vet Fak Derg, 64(3): 205-209.

Çevik, M., Tezcan, D., Sabanc1, S., İçier, F. (2016). Changes in Rheological Properties of Koruk (Unripe Grape) Juice Concentrates During Vacuum Evaporation. Academic Food Joumal/ Akademik GIDA,

Erkan, N. (2005). Changes in quality characteristics during cold storage of shucked mussels (Mytilus galloprovincialis) and selected chemical decomposition indicators. J Sci Food Agric, 85(15): 2625-2630, doi: 10.1002/jsfa.2331.

Fiallos, N.D.M., Cecchin, D., de Lima, C.O., Hirata Jr, R., Silva, E.J.N.L., Sassone, L.M. (2019). Antimicrobial effectiveness of grape seed extract against Enterococcus faecalis biofilm: A confocal laser scanning microscopy analysis. Aust Endod J, doi: $10.1111 /$ aej.12390

Guin, S., Saravanan, M., Chowdhury, G., Pazhani, G. P., Ramamurthy, T., Das, S.C. (2019). Pathogenic Vibrio parahaemolyticus indiarrhoeal patients, fish and aquatic environments and their potential for inter-source transmission. Heliyon, 5(5): e01743, doi: 10.1016/j.heliyon.2019.e01743. 
Güngörür, M.N., Mol, S. (2019). Bir g1da olarak midye. Aydn Gastronomy, 3(2): 119-127.

Hayrapetyan, H., Hazeleger, W.C., Beumer, R.R. (2012). Inhibition of Listeria monocytogenes by pomegranate (Punica granatum) peel extract in meat paté at different temperatures. Food Control, 23(1): 66-72, doi: 10.1016/j.foodcont.2011.06.012.

Ibrahim, H.M., Amin, R.A., Ghanaym, H.R. (2018). Effect of marination on Vibrio parabaemolyticus in tilapia fillets. Benha Vet Med Jl, 34(2): 234-245.

Karabiyikli, Ş., Öncül, N. (2016). Inhibitory effect of unripe grape products on foodborne pathogens. J Food Process Preser, 40(6): 1459-1465, doi:10.1111/jfpp.12731.

Karapinar, M., Sengun, I. Y. (2007). Antimicrobial effect of koruk (unripe grape-Vitis vinifera) juice against Salmonella Typhimurium on salad vegetables. Food Control,18(6): 702-706, doi:10.1016/j.foodcont.2006.03.004.

Kayhan, F.E., Sesal, N.C., Güldür, S. (2016). Kara midye'lerin (Mytilus galloprovincialis) Gram-negatif bakteri florasınin tespiti. Marmara Fen Bilimleri Dergisi, 28(2): 66-69, doi: 10.7240/mufbed.79713.

K1lınç, B., Yavuz, A.B. (2011). Üzüm ve elma sirkelerinin buzdolabında depolanmış alabalık filetolarının mikrobiyolojik ve duyusal kalitesi üzerine etkileri. Biyoloji Bilimleri Araștıma Dergisi, 4(1): 21-29.

Kışla, D. (2007). Effectiveness of lemon juice in the elimination of Salmonella Typhimurium in stuffed mussels. J Food Prot, 70(12): 2847-2850.

Kumar, S. A., Ajitha, P., Sandhya, R. (2019). Comparative evaluation of antimicrobial activity of $3 \%$ sodium hypochlorite, $2 \%$ chlorhexidine, and 5\% grape seed extract against Enterococcus faecalis and Candida albicans-An in vitro study. Drug Invention Today, 12(1).

Lytou, A.E., Nychas, G.J.E., Panagou, E.Z. (2018). Effect of pomegranate based marinades on the microbiological, chemical and sensory quality of chicken meat: A metabolomics approach. Int J Food Microbiol, 267: 42-53, doi: 10.1016/j.ijfoodmicro.2017.12.023.
Mathur, P., Schaffner, D.W. (2013). Effect of lime juice on Vibrio parahaemolyticus and Salmonella enterica inactivation during the preparation of the raw fish dish ceviche. J Food Prot, 76(6): 10271030, doi:10.4315/0362-028X.JFP-12-526.

Memar, M.Y., Adibkia, K., Farajnia, S., Kafil, H.S., Yekani, M., Alizadeh, N., Ghotaslou, R. (2019). The grape seed extract: a natural antimicrobial agent against different pathogens. Rev Med Microbiol, 30(3): 173-182, doi: 10.1097/MRM.0000000000000174.

Nawi, S.F.A.M., Zain, Z.M., Zahari, M.Z., Hamid, A.A.A., Afandi, N.F.A., Fadzilah, N.Z.H., Azmi, S.N.F. (2017). The inhibitory effect of lemon juice (citrus limon) on Vibrio parabaemolyticus in raw oyster (Crassostrea virginica). J Clin Health Sci, 2(2): 31-33.

Naz, S., Siddiqi, R., Ahmad, S., Rasool, S.A., Sayeed, S.A. (2007). Antibacterial activity directed isolation of compounds from Punica granatum.J Food Sci, 72(9): M341-M345, doi: 10.1111/j.17503841.2007.00533.x.

Newton, A.E., Garrett, N., Stroika, S.G., Halpin, J.L., Turnsek, M., Mody, R.K. (2014). Increase in Vibrio parabaemolyticus infections associated with consumption of Atlantic Coast shellfish-2013. MMWR. Morb Mortal Wkly Rep, 63(15): 335336.

Ozturk, B., Sengun, I.Y. (2019). Inactivation effect of marination liquids prepared with koruk juice and dried koruk pomace on Salmonella Typhimurium, Escherichia coli O157: H7 and Listeria monocytogenes inoculated on meat. Int $J$ Food Microbiol, 304: 32-38, doi: 10.1016/j.ijfoodmicro.2019.05.013.

Saeedi, M., Yeganegi, M., Alizadeh, B.B., Vasiee, A., Tabatabaei, Y.F. (2017). Antimicrobial effects of leek (Allium Ampeloprasum L. subsp. Iranicum) extract on some food-borne pathogens in vitro. Iran J Food Sci Technol, 14(68): 73.

Sengun, I. Y., Goztepe, E., \& Ozturk, B. (2019). Efficiency of marination liquids prepared with koruk (Vitis vinifera L.) on safety and some quality attributes of poultry meat. LWT, Food Sci Technol, 113: 108317, doi: 10.1016/j.lwt.2019.108317. 
Tomotake, H., Koga, T., Yamato, M., Kassu, A., Ota, F. (2006). Antibacterial activity of citrus fruit juices against Vibrio species.J Nutr Sci Vitaminol, 52(2): 157-160.

Tosun, Ş.Y., Alakvuk, D.Ü., Ulusoy, Ş. (2018). Quality changes of thermal pasteurized mussels (Mytilus galloprovincialis) during refrigerated storage at $4 \pm 1{ }^{\circ} \mathrm{C}$. Aquatic Sci Eng, 33(4): 117-123.

Türkyılmaz, M., Tağı, Ş., Dereli, U., Özkan, M. (2013). Effects of various pressing programs and yields on the antioxidant activity, antimicrobial activity, phenolic content and colour of pomegranate juices. Food Chem, 138(2-3): 18101818, doi: 10.1016/j.foodchem.2012.11.100.

Varlık, C., Özden, Ö., Erkan, N. and Alakavuk, D.Ü. (2007). Su Ürünlerinde Temel Kalite Kontrol. İstanbul Üniversitesi Yayın no: 4662, İstanbul.
Wu, J., Jahncke, M. L., Eifert, J.D., O'Keefe, S.F., Welbaum, G.E. (2016). Pomegranate peel (Punica granatum L) extract and Chinese gall (Galla chinensis) extract inhibit Vibrio parahaemolyticus and Listeria monocytogenes on cooked shrimp and raw tuna. Food Control, 59: 695-699, doi: 10.1016/j.foodcont.2015.06.050.

Xu, C., Yagiz, Y., Zhao, L., Simonne, A., Lu, J., Marshall, M. R. (2017). Fruit quality, nutraceutical and antimicrobial properties of 58 muscadine grape varieties (Vitis rotundifolia Michx.) grown in United States. Food Chem, 215: 149-156, doi: 10.1016/j.foodchem.2016.07.163. 